\title{
A case-only study of gene-environment interaction between genetic susceptibility variants in NOD2 and cigarette smoking in Crohn's disease aetiology
}

Katherine L Helbig ${ }^{1 *}$, Michael Nothnagel2 ${ }^{2}$, Jochen Hampe ${ }^{3}$, Tobias Balschun ${ }^{4}$, Susanna Nikolaus ${ }^{3}$, Stefan Schreiber ${ }^{3,4}$, Andre Franke ${ }^{4}$ and Ute Nöthlings ${ }^{1,5}$

\begin{abstract}
Background: Genetic variation in NOD2 and cigarette smoking are well-established risk factors for the development of Crohn's disease (CD). However, little is known about a potential interaction between these risk factors. We investigated gene-environment interactions between CD-associated NOD2 alleles and cigarette smoking in a large sample of patients with CD.

Methods: Three previously reported CD-associated variants in NOD2 (R702W, G908R, 1007fs) were genotyped in 1636 patients with CD continuously recruited between 1995 and 2010 based on physician referral. Data on history of smoking behaviour was obtained for all participants through a written questionnaire. Using a case-only design, we performed logistic regression analyses to investigate statistical interactions between NOD2 risk alleles and smoking status.

Results: We detected a significant negative interaction between carriership of at least one of the NOD2 risk alleles and history of ever having smoked $(\mathrm{OR}=0.71 ; p=0.005)$ as well as smoking at the time of $C D$ diagnosis $(\mathrm{OR}=$ $0.68 ; p=0.005)$. Subsequent separate analyses of the three variants revealed a significant negative interaction between the $1007 \mathrm{fs}$ variant and history of ever having smoked $\left(\mathrm{OR}=0.64 ; p=9 \times 10^{-4}\right)$ and smoking at the time of $\mathrm{CD}$ diagnosis $\left(\mathrm{OR}=0.53 ; p=7 \times 10^{-5}\right)$.

Conclusions: The observed significant negative gene-environment interaction suggests that the risk increase for CD conferred simultaneously by cigarette smoking and the 1007fs NOD2 polymorphism is smaller than expected and may point to a biological interaction. Our findings warrant further investigation in epidemiological and functional studies to elucidate pathophysiology as well as to aid in the development of recommendations for disease prevention.
\end{abstract}

Keywords: Gene-environment interaction, Case-only, Crohn?'?s disease, NOD2/CARD15, Cigarette smoking

\section{Background}

Crohn's disease (CD) is a common form of inflammatory bowel disease (IBD) characterised by chronic relapsing and remitting episodes of transmural inflammation of the gastrointestinal tract. High rates of $\mathrm{CD}$ are found

\footnotetext{
* Correspondence: k.helbig@iem.uni-kiel.de

'Institute for Experimental Medicine, Section of Epidemiology, ChristianAlbrechts-University of Kiel, Arnold-Heller-Straße 3, Haus 3, 24105 Kiel, Germany

Full list of author information is available at the end of the article
}

in North America (including Canada), northern Europe, and the United Kingdom, with an estimated 47,000 new cases diagnosed each year in North America and 41,000 new cases diagnosed each year in Europe [1]. The disease burden of CD is high, often associated with complications such as intestinal strictures, fistulas, and granulomas, the need for surgical intervention, and extraintestinal manifestations [2]. It is believed that immune tolerance to normal intestinal bacteria is
C Biomed Central

(c) 2012 Helbig et al; BioMed Central Ltd. This is an Open Access article distributed under the terms of the Creative Commons Attribution License (http://creativecommons.org/licenses/by/2.0), which permits unrestricted use, distribution, and reproduction in any medium, provided the original work is properly cited. 
disturbed in genetically susceptible individuals, leading to a pathogenic inflammatory response [3].

Evidence from twin and familial aggregation studies [4], as well as more recent evidence from genome-wide association studies [5] suggests that genetic factors play an important role in CD aetiology. Among the first and most consistently replicated genetic associations discovered in CD were three variants in NOD2 (nucleotidebinding oligomerisation domain containing 2; previously known as CARD15) [6,7], which represent the strongest genetic risk factors for CD identified to date [8]. NOD2, an intracellular sensor of bacteria-derived muramyl dipeptide, plays an essential role in regulating host response to intestinal bacteria $[9,10]$. The three main reported disease-associated polymorphisms (R702W, G908R, and 1007fs) all lie within or near a leucine rich repeat domain, and it is thought that these three CDassociated variants contribute to disease pathogenesis through interference with bacterial recognition $[11,12]$. Associations between CD and the three main susceptibility variants are well-established $[11,13,14]$ with a recent meta-analysis revealing disease odds ratios (OR) under a dominant genetic model of 2.2 (95\% CI 2.0-2.5) for the R702W polymorphism, 2.6 (95\% CI 2.2-2.9) for G908R, and 3.8 (95\% CI 3.4-4.3) for 1007fs [15]. When data for all three variants are combined, the disease OR associated with simple heterozygotes is 2.4 (95\% CI 2.02.8 ) and for compound heterozygotes is 9.0 (95\% CI 6.013.5) [15].

While the association of NOD2 variants with $\mathrm{CD}$ is confirmed, the relatively small effect size of disease-associated NOD2 alleles even among homozygotes [16] and the observation that NOD2 knock-out mice do not develop spontaneous intestinal inflammation [9] indicate that additional factors are necessary for disease pathogenesis. Several environmental factors such as appendectomy, dietary factors, domestic hygiene, oral contraceptive use, and childhood infections have been implicated in CD [17], but the most consistent epidemiological evidence points to a clear risk associated with cigarette smoking $[18,19]$, which is the strongest environmental risk factor identified for $\mathrm{CD}$ to date [20]. Two meta-analyses reveal that current cigarette smokers are up to twice as likely to develop CD as non-smokers (OR $=1.8-2.0)[21,22]$. Furthermore, cigarette smoking is known to compromise innate and adaptive immune responses, leading to increased susceptibility to microbial infections [23], supporting its potential role in the pathogenesis of $\mathrm{CD}$.

It has been speculated that an interaction between genetic and environmental factors is necessary for the development of complex genetic disorders including CD [24]. Although gene-environment interactions have often been invoked in explaining the aetiology of $C D$
[25], studies of these interactions in CD have thus far received little research attention. Given the established role of NOD2 in regulating innate immune responses and cigarette smoke's impact on innate immunity, it is plausible that cigarette smoking might modulate the functional consequences of $\mathrm{CD}$-associated polymorphisms in NOD2.

In this study, we used a case-only design to investigate potential gene-environment interactions between cigarette smoking and susceptibility variants in NOD2 among patients with $\mathrm{CD}$. The case-only study design quantifies gene-environment interaction using the interaction odds ratio. Using this measure, the observed effect of both variables combined is compared to the hypothetical effect size when the effect of both factors is multiplied. Accordingly, an interaction odds ratio of 1.0 suggests the absence of interaction, whereas an interaction OR significantly greater than 1.0 suggests positive (synergistic) interaction and an interaction OR significantly less than 1.0 suggests negative (antagonistic) interaction. We hypothesised that the interaction between disease-associated NOD2 alleles and history of smoking would deviate from multiplicativity with regard to risk increase for CD (i.e. interaction OR significantly greater than or less than 1.0), thus being potentially indicative of biological interaction. We further hypothesised that this deviation would be more pronounced among patients who were active smokers at the time of $\mathrm{CD}$ diagnosis. The current study represents the largest study to date to examine statistical gene-environment interactions in patients with $\mathrm{CD}$ and the first to employ a case-only design.

\section{Results}

\section{Study sample characteristics}

Table 1 provides demographic and risk factor characteristics for the 1636 participants in the analytic sample according to smoking status. Data regarding history of ever having smoked was available for all 1636 participants. Smoking status at time of diagnosis was available for 1283 (78\%) participants. The study sample included various subsamples recruited at different time points. Information on smoking at diagnosis was missing for the majority of patients in a single subsample with a high frequency of family history $(n=450$, recruited from 2002 to 2004, 68.5\% with missing data). However, a sensitivity analysis excluding this subsample did not significantly alter the results (Additional file 1: Table S1) and therefore, this subsample was included in the final analytic sample. Using a control population from the popgen biobank as a comparison group, we confirmed smoking as a risk factor for Crohn's disease in our study population (OR (95\% CI) 1.24 (1.04-1.47), $p=0.016$ for ever having smoked). Genotype data is also summarised in Table 1. Genotype status of all three polymorphisms 
Table 1 Distribution of demographic and risk factor characteristics for all participants in analytic sample by smoking status

\begin{tabular}{|c|c|c|c|c|c|c|c|c|c|c|c|c|}
\hline \multirow[b]{2}{*}{ Characteristic } & \multicolumn{2}{|c|}{$\begin{array}{c}\text { Ever } \\
\text { Smokers }\end{array}$} & \multicolumn{2}{|c|}{$\begin{array}{c}\text { Never } \\
\text { Smokers }\end{array}$} & \multirow[b]{2}{*}{$p$-value } & \multicolumn{2}{|c|}{$\begin{array}{l}\text { Smokers at } \\
\text { Diagnosis }\end{array}$} & \multicolumn{2}{|c|}{$\begin{array}{l}\text { Non-Smokers at } \\
\text { Diagnosis }\end{array}$} & \multirow[b]{2}{*}{$p$-value } & \multicolumn{2}{|c|}{$\begin{array}{c}\text { Total } \\
\text { Sample }\end{array}$} \\
\hline & $\mathrm{n}$ & $\%$ & $n$ & $\%$ & & $n$ & $\%$ & $\mathrm{n}$ & $\%$ & & $\mathrm{n}$ & $\%$ \\
\hline Total Participants $n=1636$ & 945 & $57.8 \%$ & 691 & $42.2 \%$ & & 522 & $40.7 \%$ & 761 & $59.3 \%$ & & 1636 & $100.0 \%$ \\
\hline Sex & & & & & 0.09 & & & & & 0.02 & & \\
\hline Men & 281 & $29.7 \%$ & 233 & $33.7 \%$ & & 144 & $27.6 \%$ & 258 & $33.9 \%$ & & 514 & $31.4 \%$ \\
\hline Women & 664 & $70.3 \%$ & 458 & $66.3 \%$ & & 378 & $72.4 \%$ & 503 & $66.1 \%$ & & 1122 & $68.6 \%$ \\
\hline $\begin{array}{l}\text { Age at Inclusion-Mean } \\
\text { (Standard Deviation) }\end{array}$ & 40.8 & \pm 10.9 & 36.3 & \pm 12.9 & $2 \times 10^{-13}$ & 41.1 & \pm 10.6 & 38.8 & \pm 13.5 & $6 \times 10^{-4}$ & 38.9 & \pm 12.0 \\
\hline $\begin{array}{l}\text { Age at Diagnosis-Mean } \\
\text { (Standard Deviation) }\end{array}$ & 27.4 & \pm 10.1 & 24.1 & \pm 10.1 & $7 \times 10^{-11}$ & 27.3 & \pm 9.5 & 26.0 & \pm 11.4 & 0.03 & 26 & \pm 10.3 \\
\hline Family History & & & & & 0.17 & & & & & 0.43 & & \\
\hline Yes & 229 & $24.2 \%$ & 196 & $28.4 \%$ & & 75 & $14.4 \%$ & 128 & $16.8 \%$ & & 425 & $26.0 \%$ \\
\hline No & 463 & $49.0 \%$ & 320 & $46.3 \%$ & & 295 & $56.5 \%$ & 408 & $53.6 \%$ & & 783 & $47.9 \%$ \\
\hline Unknown & 253 & $26.8 \%$ & 175 & $25.3 \%$ & & 152 & $29.1 \%$ & 225 & $29.6 \%$ & & 428 & $26.2 \%$ \\
\hline Combined Allele Analysis & & & & & $1 \times 10^{-4}$ & & & & & 0.001 & & \\
\hline Wild Type & 549 & $58.1 \%$ & 336 & $48.6 \%$ & & 311 & $59.6 \%$ & 384 & $50.5 \%$ & & 885 & $54.1 \%$ \\
\hline Carrier of $\geq 1$ risk allele & 396 & $41.9 \%$ & 355 & $51.4 \%$ & & 211 & $40.4 \%$ & 377 & $49.5 \%$ & & 751 & $45.9 \%$ \\
\hline R702W Polymorphism & & & & & 0.12 & & & & & 0.34 & & \\
\hline Wild Type (C/C) & 776 & $82.1 \%$ & 540 & $78.1 \%$ & & 429 & $82.2 \%$ & 608 & $79.9 \%$ & & 1316 & $80.4 \%$ \\
\hline Heterozygote for risk allele (C/T) & 153 & $16.2 \%$ & 134 & $19.4 \%$ & & 85 & $16.3 \%$ & 133 & $17.5 \%$ & & 287 & $17.5 \%$ \\
\hline Homozygote for risk allele (T/T) & 16 & $1.7 \%$ & 17 & $2.5 \%$ & & 8 & $1.5 \%$ & 20 & $2.6 \%$ & & 33 & $2.0 \%$ \\
\hline G908R Polymorphism & & & & & 0.93 & & & & & 0.12 & & \\
\hline Wild Type (G/G) & 858 & $90.8 \%$ & 626 & $90.6 \%$ & & 475 & $91.0 \%$ & 689 & $90.5 \%$ & & 1484 & $90.7 \%$ \\
\hline Heterozygote for risk allele (G/C) & 84 & $8.9 \%$ & 62 & $9.0 \%$ & & 47 & $9.0 \%$ & 66 & $8.7 \%$ & & 146 & $8.9 \%$ \\
\hline Homozygote for risk allele (C/C) & 3 & $0.3 \%$ & 3 & $0.4 \%$ & & 0 & $0.0 \%$ & 6 & $0.8 \%$ & & 6 & $0.4 \%$ \\
\hline 1007fs Polymorphism & & & & & $1 \times 10^{-4}$ & & & & & $7 \times 10^{-6}$ & & \\
\hline Wild Type (-/-) & 735 & $77.8 \%$ & 477 & $69.0 \%$ & & 420 & $80.5 \%$ & 524 & $68.9 \%$ & & 1212 & $74.1 \%$ \\
\hline Heterozygote for risk allele (-/C) & 174 & $18.4 \%$ & 166 & $24.0 \%$ & & 88 & $16.9 \%$ & 187 & $24.6 \%$ & & 340 & $20.8 \%$ \\
\hline Homozygote for risk allele (C/C) & 36 & $3.8 \%$ & 48 & $6.9 \%$ & & 14 & $2.7 \%$ & 50 & $6.6 \%$ & & 84 & $5.1 \%$ \\
\hline
\end{tabular}

was available for all 1636 participants. The study sample was largely comprised of women (69\%). Female participants were slightly more likely than male participants to have been smokers at the time of CD diagnosis $(p=0.02)$. Participants who had ever smoked were on average older at diagnosis (mean age ever smokers 27.4 years, never smokers 24.1 years; $p<$ 0.001 ) and at study inclusion (mean age ever smokers 40.8 years, never smokers 36.3 years; $p<0.001$ ) than those who had no history of smoking. Similarly, individuals who were smokers at the time of disease diagnosis were on average older at diagnosis (mean age smokers 27.3 years, non-smokers 26.0 years; $p=0.03$ ) and study inclusion (mean age smokers 41.1 years, non-smokers 38.8 years; $p<0.001$ ) than non-smokers at diagnosis. Carriers of at least one $\mathrm{CD}$-associated NOD2 allele were diagnosed at a younger age (mean age at diagnosis 25.1 years) than participants who were wild type at all three loci (mean age at diagnosis 26.8 years; $p<=0.001$; Additional file 1: Table S2).
Analyses of each polymorphism separately indicated that the $1007 \mathrm{fs}$ allele was the only polymorphism associated with an earlier age at diagnosis (mean age at diagnosis for carriers 24.6 years; mean age at diagnosis for non-carriers 26.5 years; $p=0.001$; Additional file 1: Table S2). Age at diagnosis was not associated with the R702W and G908R polymorphisms. Sex, age at study inclusion, and family history of IBD were not associated with genotype for any of the three risk variants (Additional file 1: Table S2). A positive family history of IBD was not associated with smoking status in probands ( $p=0.08$, Chi square analysis). Analyses comparing the study participants included and excluded from the final analyses revealed no significant differences with regard to sex, smoking status, age at study inclusion, or genotype at any of the three loci (Additional file 1: Table S3). Excluded participants were diagnosed at a slightly younger age than included participants ( 24.8 years vs. 26.8 years; $p<0.001$; Additional file 1: Table S3). 


\section{Gene-environment interaction analysis}

We observed a significant departure from multiplicativity between carriership of at least one of the three risk variants and history of ever having smoked (OR estimate of departure from multiplicativity adjusted for age at diagnosis, age at recruitment, sex, family history of IBD, and year of recruitment $(\mathrm{AOR})=0.71,95 \% \mathrm{CI} 0.56$ 0.90; Table 2) and history of smoking at the time of $C D$ diagnosis $(\mathrm{AOR}=0.68,95 \%$ CI 0.51-0.89; Table 3 ). Upon analysis of individual polymorphisms, we observed a significant departure from multiplicativity only between the $1007 \mathrm{fs}$ risk allele and history of ever having smoked (AOR $=0.64,95 \%$ CI 0.49-0.83; Table 2) and history of smoking at time of CD diagnosis $(A O R=$ 0.53, 95\% CI 0.39-0.73; Table 3). We found no evidence for interaction between the R702W and G908R risk alleles and history of ever smoking or smoking status at the time of diagnosis.

\section{Discussion}

In an investigation of statistical interactions between cigarette smoking and $\mathrm{CD}$-associated $N O D 2$ polymorphisms, we found a significant negative interaction between the NOD2 1007fs polymorphism and cigarette smoking. We did not observe this interaction for the R702W or G908R polymorphisms. For both smoking variables analysed, i.e. history of ever having smoked and smoking status at the time of diagnosis, the observed interaction OR between smoking and the $1007 \mathrm{fs}$ allele was lower than expected. These results indicate that the increase in disease risk conferred by both cigarette smoking and the $1007 \mathrm{fs}$ allele is significantly lower than would be expected under a multiplicative model. Accordingly, the lower than expected disease risk in individuals who both carry the risk allele and smoke suggests a negative interaction between both factors.

It is possible that age of disease diagnosis and family history of IBD might confound these results, especially given the earlier age of disease diagnosis associated with the $1007 \mathrm{fs}$ variant. However, our final model was adjusted for age at diagnosis and family history, which controls for potential confounding effects. Furthermore, family history of IBD was not associated with smoking status in our cohort. This indicates that age at diagnosis and family history of IBD do not confound our results.

The strong negative interaction between cigarette smoking and the $1007 \mathrm{fs}$ variant is intriguing given the conflicting data from previous research. Statistical interactions between $\mathrm{CD}$-associated NOD2 variants and smoking were previously investigated in two case-control studies, which failed to identify any statistical interactions between smoking status and NOD2 genotypes $[13,26]$. These studies, however, were limited by small sample sizes and lacked the statistical power to detect interactions of the size identified in our study. However, two small studies have suggested that smokers and nonsmokers with $\mathrm{CD}$ have differences in their genetic backgrounds, including variants in NOD2, with the $1007 \mathrm{fs}$ variant found more commonly among non-smokers $[27,28]$. These previous findings are consistent with our results of a negative interaction between cigarette smoking and the $1007 \mathrm{fs}$ allele. Taken together, these data are suggestive that cigarette smoking modifies the disease risk associated with the $1007 \mathrm{fs}$ variant, and the increase in disease risk for smokers who carry this susceptibility allele compared to non-smokers who carry this allele is significantly less than expected.

To our knowledge the current study represents the largest analysis to date of statistical gene-environment

Table 2 Departure from multiplicativity between CD-associated NOD2 alleles and ever smoking status among patients with Crohn's disease

\begin{tabular}{|c|c|c|c|c|c|c|c|c|}
\hline & \multicolumn{2}{|c|}{ Smoking status } & \multicolumn{3}{|c|}{ Unadjusted } & \multicolumn{3}{|c|}{ Adjusted* } \\
\hline & Ever smoked & Never smoked & OR & $95 \% \mathrm{Cl}$ & $p$-value & OR & $95 \% \mathrm{Cl}$ & $p$-value \\
\hline \multicolumn{9}{|l|}{ Combined Allele Analysis } \\
\hline Wild type at all 3 loci & $549(58.1 \%)$ & $336(48.6 \%)$ & 1.00 & - & - & 1.00 & - & - \\
\hline Carrier of $\geq 1$ risk allele & $396(41.9 \%)$ & $355(51.4 \%)$ & 0.68 & $0.56-0.83$ & $1 \times 10^{-4}$ & 0.71 & $0.56-0.90$ & 0.005 \\
\hline \multicolumn{9}{|l|}{ R702W Polymorphism } \\
\hline Wild type & $776(82.1 \%)$ & $540(78.1 \%)$ & 1.00 & - & - & 1.00 & - & - \\
\hline Carrier of risk allele & $169(17.9 \%)$ & $151(21.9 \%)$ & 0.78 & $0.61-1.00$ & 0.04 & 0.80 & $0.59-1.07$ & 0.14 \\
\hline \multicolumn{9}{|l|}{ G908R Polymorphism } \\
\hline Wild type & $858(90.8 \%)$ & $626(90.6 \%)$ & 1.00 & - & - & 1.00 & - & - \\
\hline Hetero- or homozygote & $87(9.2 \%)$ & $65(9.4 \%)$ & 0.98 & $0.70-1.37$ & 0.89 & 1.00 & $0.67-1.53$ & 0.96 \\
\hline \multicolumn{9}{|l|}{ 1007fs Polymorphism } \\
\hline Wild type & $735(77.8 \%)$ & 477 (69.0\%) & 1.00 & - & - & 1.00 & - & - \\
\hline Carrier of risk allele & $210(22.2 \%)$ & $214(31.0 \%)$ & 0.64 & $0.51-0.80$ & $7 \times 10^{-5}$ & 0.64 & $0.49-0.83$ & $9 \times 10^{-4}$ \\
\hline
\end{tabular}

* adjusted for sex, age at diagnosis, age at study inclusion, family history, and year of recruitment 
Table 3 Departure from multiplicativity between CD-associated NOD2 alleles and smoking status at diagnosis among patients with Crohn's disease

\begin{tabular}{|c|c|c|c|c|c|c|c|c|}
\hline & \multicolumn{2}{|c|}{ Smoking status at diagnosis } & \multicolumn{3}{|c|}{ Unadjusted } & \multicolumn{3}{|c|}{ Adjusted $^{*}$} \\
\hline & Smoker at diagnosis & Non-smoker at diagnosis & OR & $95 \% \mathrm{Cl}$ & $p$-value & OR & $95 \% \mathrm{Cl}$ & $p$-value \\
\hline \multicolumn{9}{|l|}{ Combined Allele Analysis } \\
\hline Wild type at all 3 loci & $311(59.6 \%)$ & $384(50.5 \%)$ & 1.00 & - & - & 1.00 & - & - \\
\hline Carrier of $\geq 1$ risk allele & $211(40.4 \%)$ & $377(49.5 \%)$ & 0.69 & $0.55-0.87$ & 0.001 & 0.68 & $0.51-0.89$ & 0.005 \\
\hline \multicolumn{9}{|l|}{ R702W Polymorphism } \\
\hline Wild type & $429(82.2 \%)$ & $608(79.9 \%)$ & 1.00 & - & - & 1.00 & - & - \\
\hline Carrier of risk allele & $93(17.8 \%)$ & $153(20.1 \%)$ & 0.86 & $0.65-1.14$ & 0.30 & 0.82 & $0.57-1.16$ & 0.27 \\
\hline \multicolumn{9}{|l|}{ G908R Polymorphism } \\
\hline Wild type & 475 (91.0\%) & $689(90.5 \%)$ & 1.00 & - & - & 1.00 & - & - \\
\hline Carrier of risk allele & $47(9.0 \%)$ & $72(9.5 \%)$ & 0.94 & $0.64-1.39$ & 0.78 & 0.93 & $0.57-1.49$ & 0.76 \\
\hline \multicolumn{9}{|l|}{ 1007fs Polymorphism } \\
\hline Wild type & $420(80.5 \%)$ & $524(68.9 \%)$ & 1.00 & & - & 1.00 & - & \\
\hline Carrier of risk allele & $102(19.5 \%)$ & $237(31.1 \%)$ & 0.54 & $0.41-0.70$ & $3 \times 10^{-6}$ & 0.53 & $0.39-0.73$ & $7 \times 10^{-5}$ \\
\hline
\end{tabular}

* adjusted for sex, age at diagnosis, age at study inclusion, family history, and year of recruitment

interactions in $C D$ aetiology and the first to employ a case-only design. Previous studies investigating geneenvironment interaction in CD $[13,26]$ did not employ the case-only design, which has been increasingly recognised over the last two decades as an attractive method for assessing the presence of statistical interaction [29-32]. The case-only design offers substantial increases in power as well as greater precision in estimating interactions when compared to traditional case-control designs [31].

Although our findings are promising, the current study does have limitations. The main limitation is that the case-only design only allows for the assessment of statistical interactions under a multiplicative model, which is considered by many epidemiologists to be less meaningful than an additive scale [33]. Furthermore, case-only designs are particularly sensitive to the assumption of independence of the genetic and environmental risk factors in the general population [34]. However, we observed no association between any of the $\mathrm{CD}$-associated risk alleles and history of ever having smoked in a sample of 718 German population-based controls, which supports the assumption that these risk factors are independent. Additionally, a recent metaanalysis suggests that bias in case-only studies is rare, and no differences in OR estimates between traditional case-control and case-only studies of gene-environment interactions were observed [32]. Our study was further limited by the definition of smoking status. In the questionnaire administered to participants, no definition of active smoking was specified. Participants were asked only if they had ever smoked, which may have led to misclassification of the environmental variable among some participants. However, if the rates of misclassification of smoking status and genotypes are non- differential, that is if the classification of smoking status is independent of genotype classification, as one would expect, misclassification would push the interaction OR towards unity rather than generate an inflated estimate of interaction [33].

Despite these limitations, statistical interaction represents a powerful tool to point to potentially meaningful biological interaction. Evidence from functional studies [35] and an animal model of the $1007 \mathrm{fs}$ polymorphism [10] suggests that the protein product encoded by this allele exhibits gain of function properties, resulting in an impairment of innate immune tolerance towards commensal bacteria. The three CD-associated NOD2 polymorphisms furthermore have been shown to cause a failure to induce autophagy via ATG16L1, impairing autophagic wrapping and removal of invading bacteria [36]. It has also been observed that cigarette smoke extract delays NOD2 mRNA expression and impairs NOD2 functioning in intestinal epithelial cells [37]. It is reasonable to then speculate that the detrimental gain of function effects associated with the $1007 \mathrm{fs}$ associated protein may be modulated by the biological effects of cigarette smoking. The immunosuppressive properties of nicotine, one of the best studied components of cigarette smoke, are well-established [23] and have been shown to persist several weeks after exposure [38].

Our study indicates that smoking may modify the overall disease risk associated with established genetic risk variants. Therefore, it is plausible to suggest that similar gene-environment interactions may exist that influence the clinical manifestations and severity of $C D$. Indeed it has recently been demonstrated that cigarette smoking interacts with $\mathrm{CD}$ risk alleles, including NOD2 variants, to influence disease location in patients with CD [39]. Further research is necessary to elucidate the 
potential biological mechanisms behind such gene-environment interactions as well as to understand how behaviour modification could potentially benefit patients carrying disease-associated NOD2 variants.

\section{Conclusions}

Our finding of a significant negative statistical interaction between cigarette smoking and the 1007 fs NOD2 polymorphism in patients with Crohn's disease is intriguing and warrants further investigation in epidemiological and functional studies. Confirmation of a mechanistic interaction by which cigarette smoking modulates the risk associated with disease-associated NOD2 alleles may be important in not only better understanding the biological mechanisms underlying $\mathrm{CD}$ pathogenesis, but also in developing appropriate recommendations for individuals at high risk of developing $\mathrm{CD}$.

\section{Methods}

\section{Study design}

Individuals with Crohn's disease (CD) were continuously recruited from 1995 to 2010 as part of ongoing studies for identifying genetic factors in inflammatory bowel diseases. Patients were ascertained from across Germany through physician referrals based on a positive diagnosis of $\mathrm{CD}$. Established clinical, radiologic, and endoscopic criteria were required to confirm the diagnosis of $C D$, as previously described [40-42]. A peripheral venous blood sample was obtained from each participant at time of recruitment. Informed written consent was obtained from all study participants. The study protocol was approved by the ethics committee of the University Medical Hospital Schleswig-Holstein at the ChristianAlbrechts-University of Kiel. All patients were recruited through the popgen biobank [43].

\section{Data collection \\ Study population}

A total of 2430 German individuals with Crohn's disease were eligible for participation in the current study. Participants were excluded from analyses if genotype data for any of the three risk loci were unavailable or if they were non-proband members of multiplex families and thus related to other members of the study sample. Of the multiplex families, only the index patients were included in the final study sample. Participants were included in the analysis only if genotype data were available for all three CD-associated NOD2 polymorphisms. Genotype data were unavailable for 744 individuals, excluding them from further analysis. We excluded a further 50 participants, as they were non-proband members of multiplex families. After exclusion of related individuals and those with missing genotypes, a total of 1636 participants were available for analysis.

\section{Smoking behaviour}

Participants in the study were administered a written questionnaire to obtain information on demographic characteristics, disease specific information, general medical history, family history, and history of active cigarette smoking. Participants were asked to indicate if they had ever been active smokers and were assigned either a "never smoker" or "ever smoker" status according to responses given in the questionnaire. Participants were furthermore asked to indicate if they had been smokers at the time of CD diagnosis. Participants designated as "ever smokers" were further subdivided into either "smokers at time of diagnosis" or "non-smokers at time of diagnosis".

\section{Genotyping}

DNA was extracted from peripheral blood lymphocytes from each participant using standard methods. The R702W, G908R, and 1007fs polymorphisms were genotyped in all patients using TaqMan ${ }^{\circledR}$ SNP genotyping assays as previously described [14].

\section{Statistical analysis}

Demographic and risk factor variables for the included and excluded participants were compared using a $\chi^{2}$ test for categorical variables and the independent samples $t$ test for continuous variables.

For the analysis of gene-environment interaction, we examined the effect of three established NOD2 risk polymorphisms (R702W, G908R, and $1007 \mathrm{fs}$ ) and history of having ever smoked in patients with Crohn's disease. We employed a case-only study design, which uses data only from diseased individuals to estimate statistical gene-environment interactions under a multiplicative model, assuming that the genetic and environmental exposures are independent within the general population [29-31].

Genetic exposures were coded dichotomously (i.e. present or absent) for all analyses. In an initial combined allele analysis, participants who were carriers of at least one of the three risk variants were combined into a single group and compared to participants who were wild type at all three loci. In order to determine which polymorphisms were contributing to the signal detected in the combined variant analysis, we then performed subsequent analyses of each polymorphism separately. To investigate whether deviations from multiplicativity were stronger amongst participants who were smokers at the time of diagnosis, we performed a second set of analyses examining smoking status at the time of $\mathrm{CD}$ diagnosis.

To assess departure from multiplicativity between the presence of NOD2 polymorphisms and smoking status, we performed logistic regression analyses in $\mathrm{R}$ version 2.10.1 [44]. Presence of the NOD2 risk allele(s) of the polymorphism under consideration was designated as 
the response variable, while ever smoking status was used as the predictor variable in the first set of analyses and smoking status at the time of diagnosis was used as the predictor variable in the second set of analyses. Presence of gene-environment interaction was tested using a likelihood-ratio test in the regression model. Departure from multiplicativity between risk allele under consideration and smoking status was described by estimating odds ratios (ORs) for the interaction term in the regression model and respective 95\% confidence intervals (CIs). Participants with wild type genotype and who were classified as never having smoked or as nonsmokers at the time of $\mathrm{CD}$ diagnosis were used as the reference group for all respective analyses. All analyses were adjusted for the potential confounding effects of sex, age at diagnosis, age at recruitment, family history of IBD, and year of recruitment in a multiple logistic regression model.

Power calculations were performed for the combined allele analyses and for the analyses of each polymorphism separately using Quanto version 1.2.4 [45,46]. A case-only outcome design for gene-environment interactions under a dominant genetic model was used. Established estimates of disease prevalence [47], risk allele frequencies in the German general population [16], and smoking frequency in a German population-based control sample along with disease ORs associated with cigarette smoking and $\mathrm{CD}$-associated $\mathrm{NOD} 2$ variants derived from meta-analyses $[15,22]$ were used for power calculations. Power curves for each of the eight analyses performed are presented in Additional file 2: Figure S1 and Additional file 3: Figure S2. For the analyses of statistical interaction with history of ever having smoked, the current study had $80 \%$ statistical power to detect an interaction OR of 0.73 (combined allele analysis), 0.67 (R702W), 0.41 (G908R), and 0.70 (1007fs). Our study had $80 \%$ statistical power to detect an interaction OR of 0.70 (combined allele analysis), 0.64 (R702W), 0.35 (G908R), and 0.67 (1007fs) for the analyses of interaction with smoking status at the time of diagnosis.

Conservative Bonferroni correction for eight tests at an overall alpha level of 0.05 was applied to all analyses to correct for multiple comparisons.

\section{Additional material}

Additional file 1: Table S1. Sensitivity analysis comparing geneenvironment interaction between the entire analytic sample $(n=1636)$ and a dataset excluding a subsample with incomplete smoking at diagnosis data ( $n=1186)$; all analyses adjusted for sex, age at diagnosis, age at study inclusion, family history, and year of recruitment. Table S2. Comparison of sex, age at disease diagnosis, age at study inclusion, and family history of IBD for each of the CD-associated NOD2 risk variants among all participants included in the final analytic sample $(n=1636)$. Table S3. Comparison of demographic and risk variables between participants included and excluded from the final analytic study sample.
Additional file 2: Figure S1. Estimates of statistical power to detect various interaction ORs for each of the four analyses examining history of ever having actively smoked. $\mathrm{n}=1636$.

Additional file 3: Figure S2. Estimates of statistical power to detect various interaction ORs for each of the four analyses examining smoking status at time of CD diagnosis. Combined allele analysis $n=1283$.

\section{Acknowledgements}

This study was supported by the German National Genome Research Network (NGFNplus; 01GS0809) and by the German Research Foundation (DFG) Excellence Cluster "Inflammation at Interfaces". None of the funding organisations had any influence on the design, conduct, or conclusions of the study.

\section{Author details}

'Institute for Experimental Medicine, Section of Epidemiology, ChristianAlbrechts-University of Kiel, Arnold-Heller-Straße 3, Haus 3, 24105 Kiel, Germany. ${ }^{2}$ Institute of Medical Informatics and Statistics, Christian-AlbrechtsUniversity of Kiel, Kiel, Germany. ${ }^{3}$ Department of General Internal Medicine, University Hospital Schleswig-Holstein, Christian-Albrechts-University of Kiel, Kiel, Germany. ${ }^{4}$ Institute for Clinical Molecular Biology, Christian-AlbrechtsUniversity of Kiel, Kiel, Germany. ${ }^{5}$ Biobank popgen, University Hospital Schleswig-Holstein, Christian-Albrechts-University of Kiel, Kiel, Germany.

\section{Authors' contributions}

$\mathrm{KLH}$ designed the study, performed data analysis and interpretation, and wrote the manuscript. MN provided statistical and interpretational advice and support. JH, TB, and AF provided genotype and phenotype data for all participants. JH, SN, and SS were instrumental in participant recruitment, data collection, and phenotyping of participants. UN supervised and designed the study and wrote the manuscript. All authors reviewed, edited, and approved the final paper.

Received: 3 November 2011 Accepted: 14 March 2012 Published: 14 March 2012

\section{References}

1. Loftus EV Jr: Clinical epidemiology of inflammatory bowel disease: incidence, prevalence, and environmental influences. Gastroenterology 2004, 126:1504-1517.

2. Abraham C, Cho JH: Inflammatory bowel disease. N Engl J Med 2009, 361:2066-2078.

3. Cho JH: The genetics and immunopathogenesis of inflammatory bowel disease. Nat Rev Immunol 2008, 8:458-466.

4. Halme L, Paavola-Sakki P, Turunen U, Lappalainen M, Farkkila M, Kontula K: Family and twin studies in inflammatory bowel disease. World J Gastroenterol 2006, 12:3668-3672.

5. Franke A, McGovern DP, Barrett JC, Wang K, Radford-Smith GL, Ahmad T, Lees CW, Balschun T, Lee J, Roberts $R$, et al: Genome-wide meta-analysis increases to 71 the number of confirmed Crohn's disease susceptibility loci. Nat Genet 2010, 42:1118-1125.

6. Hugot JP, Chamaillard M, Zouali H, Lesage S, Cezard JP, Belaiche J, Almer S, Tysk C, O'Morain CA, Gassull M, et al: Association of NOD2 leucine-rich repeat variants with susceptibility to Crohn's disease. Nature 2001, 411:599-603.

7. Ogura Y, Bonen DK, Inohara N, Nicolae DL, Chen FF, Ramos R, Britton H, Moran T, Karaliuskas R, Duerr RH, et al: A frameshift mutation in NOD2 associated with susceptibility to Crohn's disease. Nature 2001, 411:603-606.

8. Barrett JC, Hansoul S, Nicolae DL, Cho JH, Duerr RH, Rioux JD, Brant SR, Silverberg MS, Taylor KD, Barmada MM, et al: Genome-wide association defines more than 30 distinct susceptibility loci for Crohn's disease. Nat Genet 2008, 40:955-962.

9. Kobayashi KS, Chamaillard M, Ogura Y, Henegariu O, Inohara N, Nunez G, Flavell RA: Nod2-dependent regulation of innate and adaptive immunity in the intestinal tract. Science 2005, 307:731-734.

10. Maeda S, Hsu LC, Liu H, Bankston LA, limura M, Kagnoff MF, Eckmann L, Karin M: Nod2 mutation in Crohn's disease potentiates NF-kappaB activity and IL-1 beta processing. Science 2005, 307:734-738. 
11. Lesage S, Zouali H, Cezard JP, Colombel JF, Belaiche J, Almer S, Tysk C, O'Morain C, Gassull M, Binder V, et al: CARD15/NOD2 mutational analysis and genotype-phenotype correlation in 612 patients with inflammatory bowel disease. Am J Hum Genet 2002, 70:845-857.

12. van Heel DA, Hunt KA, King K, Ghosh S, Gabe SM, Mathew CG, Forbes A, Playford RJ: Detection of muramyl dipeptide-sensing pathway defects in patients with Crohn's disease. Inflamm Bowel Dis 2006, 12:598-605.

13. Brant SR, Wang MH, Rawsthorne P, Sargent M, Datta LW, Nouvet F, Shugart YY, Bernstein CN: A population-based case-control study of CARD15 and other risk factors in Crohn's disease and ulcerative colitis. Am J Gastroenterol 2007, 102:313-323.

14. Hampe J, Cuthbert A, Croucher PJ, Mirza MM, Mascheretti S, Fisher S, Frenzel H, King K, Hasselmeyer A, MacPherson AJ, et al: Association between insertion mutation in NOD2 gene and Crohn's disease in German and British populations. Lancet 2001, 357:1925-1928.

15. Yazdanyar S, Weischer M, Nordestgaard BG: Genotyping for NOD2 genetic variants and crohn disease: a metaanalysis. Clin Chem 2009, 55:1950-1957.

16. Hugot JP, Zaccaria I, Cavanaugh J, Yang H, Vermeire S, Lappalainen M, Schreiber S, Annese V, Jewell DP, Fowler EV, et al: Prevalence of CARD15/ NOD2 mutations in Caucasian healthy people. Am J Gastroenterol 2007, 102:1259-1267.

17. Lakatos PL: Environmental factors affecting inflammatory bowel disease: have we made progress? Dig Dis 2009, 27:215-225.

18. Silverstein MD, Lashner BA, Hanauer SB, Evans AA, Kirsner JB: Cigarette smoking in Crohn's disease. Am J Gastroenterol 1989, 84:31-33.

19. Somerville KW, Logan RF, Edmond M, Langman MJ: Smoking and Crohn's disease. Br Med J (Clin Res Ed) 1984, 289:954-956.

20. Aldhous MC, Satsangi J: The impact of smoking in Crohn's disease: no smoke without fire. Frontline Gastroenterol 2010, 1:156-164.

21. Calkins BM: A meta-analysis of the role of smoking in inflammatory bowel disease. Dig Dis Sci 1989, 34:1841-1854.

22. Mahid SS, Minor KS, Soto RE, Hornung CA, Galandiuk S: Smoking and inflammatory bowel disease: a meta-analysis. Mayo Clin Proc 2006, 81:1462-1471.

23. Sopori M: Effects of cigarette smoke on the immune system. Nat Rev Immunol 2002, 2:372-377.

24. Xavier RJ, Podolsky DK: Unravelling the pathogenesis of inflammatory bowel disease. Nature 2007, 448:427-434.

25. Ahmed FE: Role of genes, the environment and their interactions in the etiology of inflammatory bowel diseases. Expert Rev Mol Diagn 2006, 6:345-363.

26. Ernst A, Jacobsen B, Ostergaard M, Okkels $H$, Andersen V, Dagiliene E, Pedersen IS, Thorsgaard N, Drewes AM, Krarup HB: Mutations in CARD15 and smoking confer susceptibility to Crohn's disease in the Danish population. Scand J Gastroenterol 2007, 42:1445-1451.

27. de Diego C, Alcantara M, Valle J, Repiso A, Carrobles JM, Martinez-Castro P: Influence of smoking habits and CARD15 mutations on the onset of Crohn's disease. Scand J Gastroenterol 2006, 41:1209-1211.

28. van der Heide F, Nolte IM, Kleibeuker JH, Wijmenga C, Dijkstra G, Weersma RK: Differences in genetic background between active smokers, passive smokers, and non-smokers with Crohn's disease. Am J Gastroenterol 2010, 105:1165-1172.

29. Begg CB, Zhang ZF: Statistical analysis of molecular epidemiology studies employing case-series. Cancer Epidemiol Biomarkers Prev 1994, 3:173-175.

30. Khoury MJ, Flanders WD: Nontraditional epidemiologic approaches in the analysis of gene-environment interaction: case-control studies with no controls! Am J Epidemiol 1996, 144:207-213.

31. Piegorsch WW, Weinberg CR, Taylor JA: Non-hierarchical logistic models and case-only designs for assessing susceptibility in population-based case-control studies. Stat Med 1994, 13:153-162.

32. Dennis J, Hawken S, Krewski D, Birkett N, Gheorghe M, Frei J, McKeownEyssen $\mathrm{G}$, Little J: Bias in the case-only design applied to studies of geneenvironment and gene-gene interaction: a systematic review and metaanalysis. Int J Epidemiol 2011, 40:1329-1341.

33. Greenland S, Lash TL, Rothman KJ: Concepts of Interaction. In Modern Epidemiology.. 3 edition. Edited by: Rothman KJ, Greenland S, Lash TL. Philadelphia: Lippincott Williams 2008:71-83.

34. Albert PS, Ratnasinghe D, Tangrea J, Wacholder S: Limitations of the caseonly design for identifying gene-environment interactions. Am J Epidemiol 2001, 154:687-693.
35. Noguchi E, Homma Y, Kang X, Netea MG, Ma X: A Crohn's diseaseassociated NOD2 mutation suppresses transcription of human IL10 by inhibiting activity of the nuclear ribonucleoprotein hnRNP-A1. Nat Immunol 2009, 10:471-479.

36. Cooney R, Baker J, Brain O, Danis B, Pichulik T, Allan P, Ferguson DJ, Campbell BJ, Jewell D, Simmons A: NOD2 stimulation induces autophagy in dendritic cells influencing bacterial handling and antigen presentation. Nat Med 2010, 16:90-97.

37. Aldhous MC, Soo K, Stark LA, Ulanicka AA, Easterbrook JE, Dunlop MG, Satsangi J: Cigarette smoke extract (CSE) delays NOD2 expression and affects NOD2/RIPK2 interactions in intestinal epithelial cells. PLOS One 2011, 6:e24715.

38. Geng Y, Savage SM, Razani-Boroujerdi S, Sopori ML: Effects of nicotine on the immune response. II. Chronic nicotine treatment induces T cell anergy. J Immunol 1996, 156:2384-2390.

39. Chen H, Lee A, Bowcock A, Zhu W, Li E, Ciorba M, Hunt S: Influence of Crohn's disease risk alleles and smoking on disease location. Dis Colon Rectum 2011, 54:1020-1025.

40. Lennard-Jones JE: Classification of inflammatory bowel disease. Scand J Gastroenterol Supp/ 1989, 170:2-6, discussion 16-19.

41. Nikolaus S, Schreiber S: Diagnostics of inflammatory bowel disease. Gastroenterology 2007, 133:1670-1689.

42. Truelove SC, Pena AS: Course and prognosis of Crohn's disease. Gut 1976, 17:192-201.

43. Krawczak M, Nikolaus S, von Eberstein H, Croucher PJ, El Mokhtari NE, Schreiber S: PopGen: population-based recruitment of patients and controls for the analysis of complex genotype-phenotype relationships. Community Genet 2006, 9:55-61.

44. R Development Core Team: R Foundation for Statistical Computing Vienna: $R$ Development Core Team; 2010.

45. Gauderman W, Morrison J: QUANTO 1.1: A computer program for power and sample size calculations for genetic-epidemiology studies. 2006 [http://hydra.usc.edu/gxe].

46. Gauderman WJ: Sample size requirements for matched case-control studies of gene-environment interaction. Stat Med 2002, 21:35-50.

47. Loftus EV Jr, Silverstein MD, Sandborn WJ, Tremaine WJ, Harmsen WS, Zinsmeister AR: Crohn's disease in Olmsted County, Minnesota, 19401993: incidence, prevalence, and survival. Gastroenterology 1998 114:1161-1168.

\section{Pre-publication history}

The pre-publication history for this paper can be accessed here: http://www.biomedcentral.com/1471-2350/13/14/prepub

doi:10.1186/1471-2350-13-14

Cite this article as: Helbig et al:: A case-only study of gene-environment interaction between genetic susceptibility variants in NOD2 and cigarette smoking in Crohn's disease aetiology. BMC Medical Genetics 2012 13:14.

\section{Submit your next manuscript to BioMed Central and take full advantage of:}

- Convenient online submission

- Thorough peer review

- No space constraints or color figure charges

- Immediate publication on acceptance

- Inclusion in PubMed, CAS, Scopus and Google Scholar

- Research which is freely available for redistribution

Submit your manuscript at www.biomedcentral.com/submit
C Biomed Central 